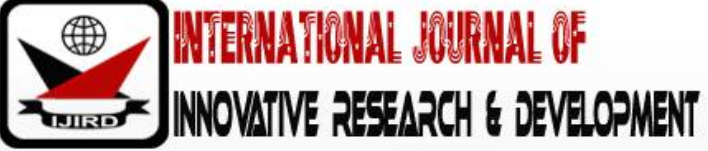

ISSN 2278 - 0211 (Online)

\section{Influence of Devolution on Maternal Health Care Service Provision in Uasin Gishu County in Kenya}

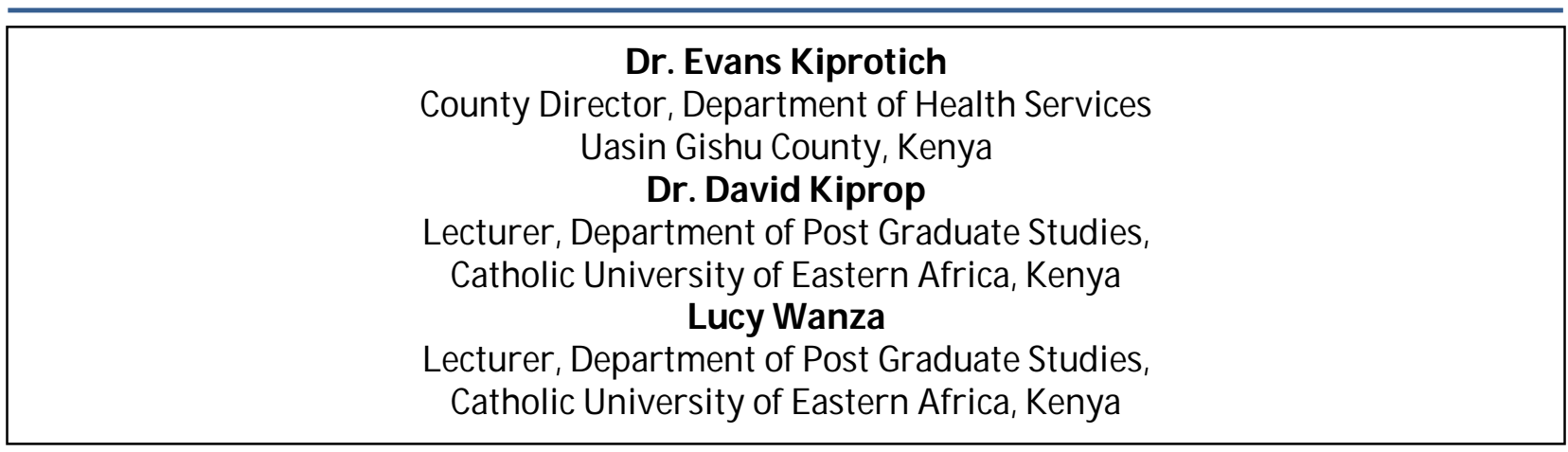

\begin{abstract}
The inadequacy of internal health care service despite the anticipated devolution/ decentralization advantage is still a matter of concern. Kenya maternal health care still faces challenges including, lack of access to quality maternal health services including ante-natal, delivery, and post-natal services. Access to skilled delivery is a particular challenge. The study aimed to assess the influence of devolution on maternal health care service provision in Uasin Gishu County, Kenya. The survey study guided by the McKinsey's 7S theory had a sample size of 77 respondents. The study employed simple random sampling. Questionnaires, interview guide and secondary data were used to collect the data. The study adopted both the qualitative and quantitative analysis in order to achieve its objective. The study concluded that devolution strategy on maternal health care was important only to the extent of assisting in the governing of maternal health services but it did not directly influence provision of maternal health care. The study recommended that the county health care units should conduct wide access campaigns targeting more women of reproductive age to inform them on the new level of service delivery in the county.
\end{abstract}

Keywords: Maternal health, service provision, devolution, ANC

\section{Introduction}

Devolution of government functions leads to decentralization of most of its functions relating to different ministries. Health systems, including maternal health care, are also being decentralized. Decentralization of health systems specifically the health care systems is defined as the process by which authority, functions and financial resources are progressively transferred to lower level units (Hardee \& Smith, 2000). The aim of decentralization is to improve the effectiveness and efficiency of the maternal health care system by developing health systems that are appropriate and accountable to local needs and which allows managers to manage (Bossert, 2007). In the health sector, the initial process has usually involved de-concentration of powers, with decentralization only taking place when it is part of the wider political agenda of local government, (Hardee \& Smith, 2000).

Although there are now a number of positive experiences with decentralization, there may be adverse effects due to local disagreement with progressive central policies. A number of process indicators, including deliveries conducted by a skilled attendant, can be used to track progress towards maternal mortality reduction goals in a decentralized maternal health care system. These indicators, which measure changes in the availability and quality of services, can potentially be used to measure changes occurring as a result of health systems reform. The lessons learnt must be incorporated into future policy and practice so that the reform process results in improvements in both quality, and equity of access to maternal health care (Soresh, 2013).

Globally, decentralization of maternal health services has been most successful in countries where the process took place slowly in line with improvements in local capacity. This suggests that the process may be better suited to more mature and developed health systems (Aitken, 2009). There seems to be a tendency to underestimate the complex nature of the devolved process and to introduce devolution of maternal health care as a reform when the public health system is in crisis. This results in exacerbating the mismanagement problems and the neglect of health services (Hardee \& Smith 2000). Evidence from Indonesia and Pakistan suggests that a positive feature of devolution of maternal health care has been the emphasis on development of the district health system (DHS) that operate maternal health as a decentralized function. Agyepong, (1999) made the point that in India utilization of ante natal care did not increase as expected after 
decentralization because Maternal Child Health services continued to be seen as divisional responsibility rather than a district essential service (Agyepong, 1999). It is difficult to be certain of the extent to which decentralization has supported maternity services. However, it is argued that a functioning district system has the "potential" to provide the continuum of care needed for effective referral from communities to emergency obstetric care facilities (Kalisten, 2012).

African countries have slowly, over the years, adopted devolution of the health service especially in maternal health care. Despite these efforts however, a study by Olen, (2012) on the effects of decentralization on maternal and child health services (MCH) in African countries suggests that increased local autonomy in the provision of maternal health services has taken place to a very small extent and the utilization of these services has not increased significantly. Activities that have been, to a small extent, successful have included the transferring management decisions regarding maternal health and other government services to local districts. Reform initiatives have given more political and administrative autonomy to local authorities, and have included the implementation of user fees, in not only maternal health care, but in health facilities in general to raise local revenue for district programs. In addition, efforts have been made to increase the participation of health service consumers in matters concerning their health and to integrate other service providers, such as nongovernmental organizations (NGOs) and traditional health providers, into the formal system. For example, in Uganda, maternal health care has been made a priority in public provisioning and policies have been enacted to improve maternal healthcare. Though decentralization has brought physical health infrastructure to closer proximity in rural areas, specific services for maternal healthcare are not necessarily provided at these health centers (Doesentin, 2012).

Before devolution, more than 90 percent of Kenyan women received antenatal care from a medical professional but fewer than half of all births used to take place in a health facility (Kenya Demographic Health Survey 2008-2009). The prevalence of home births played a large role in the country's high maternal death rate which continued to rise in the later years. By around 2008, Kenya had about 488 deaths per every 100,000 live births per year, largely because women did not give birth under the care of skilled health providers. These high rates of maternal deaths were attributed to well-known and preventable causes. They include obstructed labour, complications of unsafe abortion, infections, hemorrhage, and high blood pressure. Most of these deaths could have been avoided if the mother was managed at a health facility by a qualified health professional (Karim, 2013).

After Devolution, countdown statistics to MDG (2014) show a significant decline in maternal mortality ratio currently standing at 400 deaths per every 100,000 live births with the sharpest decline being witnessed between 2013 and 2014. Many factors could have contributed to this including the government's commitment to provide free maternal health services which is expected to encourage more women to deliver at health facilities and to result in fewer maternal deaths (Bilsend, 2014). In Uasin Gishu County, efforts have been made to increase the participation of health service consumers in matters concerning their health. There are promising results being witnessed slowly but a myriad of challenges still faces the devolution process especially in trying to achieve the goals on maternal mortality rate.

Ideally, devolution in Kenya in the health sector is expected to help reduce the Maternal Mortality Ratio (MMR) from the current 448 deaths per every 100,000 lives per birth to the Millennium Development Goals (MDG) target of 147 deaths per every 100,000 lives per birth. This is meant to be achieved within a period of at least five years after devolution because of the improved efficiency of the public sector through decentralization, concentration of limited government finances on an essential package of services, development of alternative financing mechanisms at the local levels, increasing involvement of the private sector through contracting and regulation at the local level and, introducing sustainability and greater government ownership through sector wide approaches, all of which are introduced by decentralization of maternal health care.

However, in Kenya maternal health care still faces challenges including, lack of access to quality maternal health services, including ante-natal, delivery, and post-natal services. Although health sector infrastructure has grown over the past decade, many women still live at a considerable distance from health facilities, cannot afford to pay fees for maternal services, and/ or face other barriers to accessing quality care. Access to skilled delivery is a particular challenge. Overall, only $44 \%$ of births in Kenya are delivered under the supervision of a skilled birth attendant, well below the target of $90 \%$ of deliveries by this year. Traditional birth attendants continue to assist with $28 \%$ of births, relatives and friends with $21 \%$, and in $7 \%$ of births, mothers receive no assistance at all (Kalisten, 2012).

In Uasin Gishu County and Kenya at large, devolution of health service is a new phenomenon and therefore no up to date information on the effect of devolution on provision of health services. This study is expected to shade light and generate new ideas that may lead to better understanding and management of health service delivery in public health facilities in the County and the country at large.

\subsection{Conceptual Framework}

The conceptual framework is guided by McKinsey's 7S theory by Richard Pascale (1981). The framework illustrated identifies the independent and the dependent variables of the study. The independent variable is devolution while the dependent variable is the maternal health service provision. 


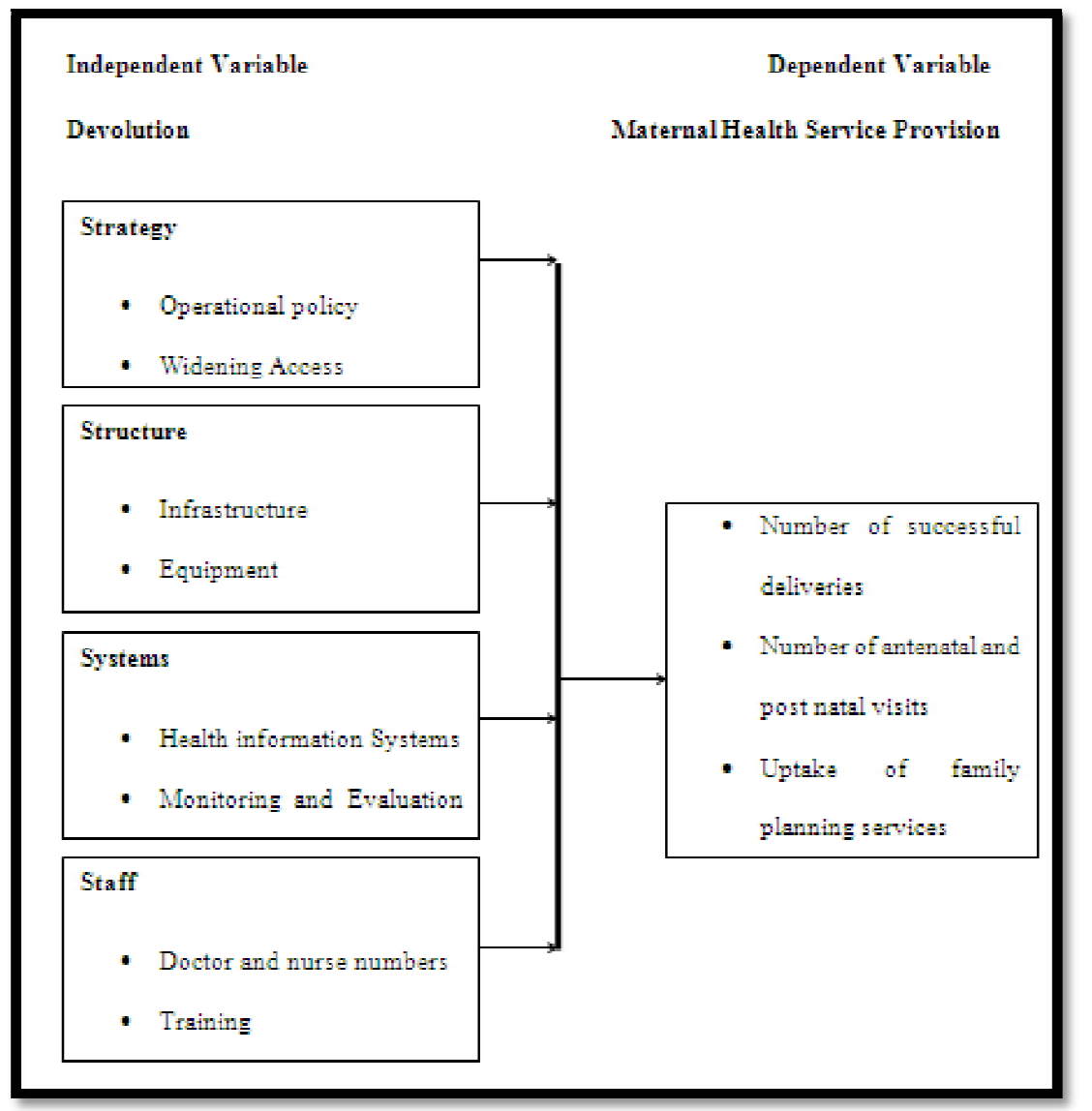

Figure 1: Conceptual Framework

Source: Author 2015

In devolved maternal health care, the systematic actions and the allocation of resources to achieve the organizational objectives and aims are referred to as Strategy. Strategy in this case refers to the operational policy developed, widening of access and the creation of awareness of the maternal health care.

Structure is the organizational structure or the hierarchy of the organization that comprises of the authority and responsibility relationships in the firm. In devolved maternal health care, structure refers to the infrastructure, equipment and the accountability and supervisory mechanisms put in place to ensure the success of the devolved maternal health care system.

Systems refer to the procedures and processes such as information systems, manufacturing processes, budgeting and control processes. With regard to the devolved maternal health care, systems refer to the health information systems used to capture data, the monitoring and evaluation systems and the supply chain function that ensure sufficient supply of drugs.

The term Staff refers to the people in the organization and their socialization into the organizational culture. This includes Staffing that is the filling, and keeping filled positions in the organizational structure through identifying workforce requirements, recruiting, selecting, placing, promoting, appraising, planning the careers, compensating, and training or otherwise developing both candidates and current job holders to accomplish their tasks effectively and efficiently.

Maternal health is the health of women during pregnancy, childbirth, and the postpartum period. It encompasses the health care dimensions of family planning, preconception, prenatal, and postnatal care in order to reduce maternal morbidity and mortality. Preconception care can include education, health promotion, screening and other interventions among women of reproductive age to reduce risk factors that might affect future pregnancies. The goal of prenatal care is to detect any potential complications of pregnancy early, to prevent them if possible, and to direct the woman to appropriate specialist medical services as appropriate. Postnatal care issues include recovery from childbirth, concerns about newborn care, nutrition, breastfeeding, and family planning.

Maternal healthcare service provision therefore encompasses all health-related activities geared towards prevention and control of causes of maternal morbidity and mortality.

\section{Methodology}

\subsection{Research Design}

Research design refers to the way a study is planned and conducted (Polonsky and Weller, 2009). The best design depends on the research question as well as the orientation of the researcher (Robson, 2003). The study used a crosssectional survey research design. The design was selected because the design allows the study collect varied responses and also ensures collection of quantitative data that can be used for predicting future outcomes of dependent variables. This research design utilizes the use of questionnaires and interview schedule to gather the opinions of the respondents 
regarding the issue under study. The survey research design emphasizes that subjects most suited to survey research are those which can be accurately measured by subject response

\subsection{Target Population}

Mugenda and Mugenda (2003), defines target population as an entire group of individuals, events or objects having common observable characteristics. The study target population comprised of management personnel and care givers who have been working in Uasin Gishu County for at least two years, such as nurses who run maternal care services, officers in charge of maternal health care in Sub-County hospitals and health centers. The target population was therefore, comprised of health care workers from sub county hospitals and health centres serving in public health facilities in Uasin Gishu County. The officer in charge of maternal health care services at the Sub County hospital also coordinates the services in their respective sub county. The sample size of the study was calculated using the formula recommended by Mugenda and Mugenda (2003) as follows

$$
\mathrm{nf}=\frac{\mathrm{n}}{(1+\mathrm{n} / \mathrm{N})}
$$

Where;

$\mathrm{nf}=$ Sample size $($ when the population is less than 10,000$)$.

$\mathrm{n}=$ Sample size (when the population is more than 10,000); 384

$\mathrm{N}=$ Estimate of the population size; 97 respondents

Therefore, the sample size of the study will therefore be;

$\mathrm{nf}=$

$$
\underline{384} \underline{1+384}
$$

97

Desired Sample Size was therefore comprised of 77 respondents.

\subsection{Research Instruments}

The study employed the use of questionnaires and interview schedules to collect data for the research.

\subsubsection{Questionnaire}

A questionnaire is a research tool that gathers data over a large sample (Nsubuga, 2000). The questionnaire was the most appropriate research tool as it allowed the researcher to collect information from a large sample with diverse background; the questionnaires were used to collect data from maternal health caregivers. The first section captured particulars of the respondent such as work experience and experience in current position for the respondents.

The second part of the questionnaires had questions grouped according to the themes of the study. Close-ended and open-ended questions were used; the Likert scale to measure the respondents' level of agreement with statements; these generated quantitative data for the study. The questionnaires were preferably used because they could be used to gather a large amount of data in a reasonably quick pace. The data gathered using the questionnaires was coded for easy analysis.

\subsubsection{Interview Guide}

This is a data collection technique in which an interviewer physically meets the respondent, reads them the same set of questions in a predetermined order, and records his or her response to each. The interview schedule was used to collect data from the officers in charge of maternal Child health care Clinics in the Sub-County hospitals. This was because they are manageable to interview. This involved face to face interview between the researcher and the respondent. Structured interviews were easy to carry out because the questions were prepared in advance (Foddy et.al 2001).

\subsection{Secondary Sources}

This was collected from hospital records which includes documented information from past hospital surveys and other reports from the ministry of health relating to the region's maternal health care services.

\subsection{Validity of Research Instruments}

According to Paton (2002) validity is quality attributed to proposition or measures to the degree to which they conform to establish knowledge or truth. An attitude scale is considered valid, for example, to the degree to which its results conform to other measures of possession of the attitude. Validity therefore refers to the extent to which an instrument can measure what it ought to measure. It therefore refers to the extent to which an instrument asks the right questions in terms of accuracy.

Validity of an instrument included the face and the content validity. According to Oso et al (2005) validity is the success of the scale in measuring what it sets out to measure so that the differences in individual scores can be taken as representing true differences in the characteristic under study. The instruments of data collection were sub-divided as per the variables and research questions. Content validity of the instrument was determined through expert judgment which involved discussing items in the instrument with the supervisor and colleagues. The suggestion for change was incorporated in the final instrument used in the study. 


\subsection{Reliability of Research Instruments}

According to Ng'ang'a et al (2009), an instrument is considered reliable when it is able to elicit the same responses each time it is administered. Reliability is concerned with precision and accuracy. Poor reliability degrades precision of a single measurement and reduces ability to track (Mislevy 2004). Reliability is a quality attributed to proposition or measures to the degree to which they produce consistent results. An attitude scale is considered reliable, for example, to the degree to which the same respondents, or very similar respondents, receive the same or very similar score upon repeated testing. According to Mugenda and Mugenda (1999), the reliability of an instrument is the measure of the degree to which a research instrument yields consistent results or data after repeated trials. The study employed the Cronbach's alpha coefficient to measure the internal consistency of the questionnaire. A reliability value that was greater than 0.7 was acceptable in research (Hair et al., 2006). According to Ng'ang'a et al (2009) supports that correlation of 0.7 is acceptable threshold, and thus the questionnaire will be deemed reliable if it scores above 0.7; this will establish the extent to which the questionnaire elicits the same responses every time it is administered.

\subsection{Description of Data Collection Procedures}

The researcher sought a consent letter from the university, NACOSTI (National Council of Science and Technology) and County Health Department. The researcher administered the questionnaires to the sample population, and also there to clarify in case there was need for clarifications. The researcher left the questionnaires with the respondents who wished to answer the questions later and then collected the questionnaires before the end of the day. Interviews were conducted as per the dates that were agreed upon by the management staff and were conducted for a period of 30 minutes.

\subsection{Description of Data Analysis Procedures}

The data collected from the research instruments was entered into SPSS version 20.0 and checked for any data entry error before data analysis began. The study adopted both the qualitative and quantitative analysis in order to achieve the research questions of the study. Descriptive statistics (frequency analysis) were performed for presenting and analyzing the data. The inferential statistics involved the use of multiple regression analysis technique. The final model achieved thus contained only statistically significant factors at an alpha level of 0.05 .

The model was in the form of:

$\mathrm{Y}=\mathrm{b}_{0}+\mathrm{b}_{1} \mathrm{X}_{1}+\mathrm{b}_{2} \mathrm{X}_{2}+\mathrm{b}_{3} \mathrm{X}_{3}+\mathrm{b}_{4} \mathrm{X}_{4}+\mathrm{e}$

Where:

$\mathrm{X}_{=}$The independent variables $. \quad \mathrm{X}_{1}-$ Strategy

$\mathrm{X}_{2}$ Structure

$\mathrm{X}_{3}$ - Systems

$\mathrm{X}_{3}-$ Staff

$\mathrm{Y}=$ The dependent variable (Provision of maternal Health Care)

$\mathrm{b}=$ Independent Variable Coefficients

$\mathrm{e}=$ Error margin

\subsection{Ethical Approval}

Informed consent was obtained from individual participants before starting the study, after they had read the participant information sheet. Permission to conduct this study was granted by The Catholic University of Eastern Africa and the County Director of Health Uasin Gishu County, Kenya in January 2015. Participants' confidentiality and anonymity were maintained throughout by ensuring names were not reported in the findings. In addition, participants were free to participate, answer questions partially decline to answer or even terminate the interview at any stage should they wish to do so.

\section{Study Findings}

\subsection{Response Rate}

The study targeted a sample population of 77 respondents and distributed questionnaires to them. The respondents were very cooperative and all the questionnaires were answered and returned to the researcher. The response rate was therefore $100 \%$ which was very suitable for the study. The researcher also collected secondary data from the county who were very cooperative in providing the information the study required. The researcher collected data that covered two years before devolution and two years after devolution for comparative purposes.

\subsection{Background Information}

The study sought to determine the background information of the respondents in an effort to ensure that sampling was effectively done. The study sought to determine the work experience of the respondents and how long they had worked in their current positions. The study findings are presented in Table 1 


\begin{tabular}{|c|c|c|c|}
\hline \multirow{4}{*}{ Work Experience } & & Frequency & Percent \\
\cline { 2 - 4 } & LESS THAN 3 YEARS & 3 & 3.9 \\
\cline { 2 - 4 } & BETWEEN 4-7 YEARS & 14 & 18.2 \\
\cline { 2 - 4 } & BETWEEN 8-12 YEARS & 18 & 23.4 \\
\cline { 2 - 4 } & OVER 13 YEARS & 42 & 54.5 \\
\cline { 2 - 4 } & Total & 77 & 100 \\
\hline \multirow{4}{*}{ Years in current position } & & Prequency & 33.8 \\
\cline { 2 - 4 } & LESS THAN 3 YEARS & 26 & 40.3 \\
\cline { 2 - 4 } & BETWEEN 4-7 YEARS & 31 & 10.4 \\
\cline { 2 - 4 } & BETWEEN 8-12 YEARS & 8 & 15.6 \\
\cline { 2 - 4 } & OVER 13 YEARS & 12 & 100 \\
\cline { 2 - 4 } & Total & 77 & \\
\hline
\end{tabular}

Table 1: Background Information of the Respondents

$$
\mathrm{N}=77
$$

Source: Research Data (2015)

The findings on the work experience of the respondents indicate that $54.5 \%$ had a work experience of over 13 years, $23.4 \%$ of between $8-12$ years, $18.2 \%$ between $4-7$ years and $3.9 \%$ of less than 3years.

The findings on the period of time the respondents had been in their current position indicate that $40.3 \%$ for a period of between $4-7$ years, 33.8\% less than 3 years, $15.6 \%$ for over 13 years while $12.4 \%$ were for a period between $8-12$ years.

\subsection{Findings on Devolution Strategy of Maternal Health Care}

The study sought to determine the extent to which devolution strategy in the health care had affected the provision of maternal health care. The findings are represented in Table 1

\begin{tabular}{|c|c|c|c|c|}
\hline A1 & The county has issued a policy to assist govern maternal health \\
care services & 2.86 & \% mean & Std. Deviation \\
\hline A2 & $\begin{array}{c}\text { There are defined strategies as to how to reach more pregnant } \\
\text { mothers in the rural areas. }\end{array}$ & 2.90 & $58 \%$ & 1.33 \\
\hline A3 & $\begin{array}{c}\text { The county in collaboration with the hospital conducts wide } \\
\text { access campaigns targeting more pregnant mothers frequently }\end{array}$ & 2.77 & $55.4 \%$ & 1.26 \\
\hline
\end{tabular}

Table 2: Influence of Devolution Strategy on Maternal Health Care

$$
\mathrm{N}=77
$$

Source: Research Data (2015)

The findings on the effect of devolution strategy of maternal health care indicate that $58 \%$ of the respondents were of the opinion that there were defined strategies as to how to reach more pregnant mothers in the rural areas, $57.2 \%$ felt that the county has issued a policy to assist govern maternal health care services while $55.4 \%$ said the county in collaboration with the hospital conducts wide access campaigns targeting more pregnant mothers frequently

The study findings also indicated that some of the new policy documents that were developed relating to maternal health care provision were free maternity services, beyond zero campaign and mobile clinics.

The study determined that health care before and after the devolution in terms of policy change and its effectiveness in provision of maternal health care provision had increased in maternal health care demand bringing the services close to the people although strained in capacity.

\subsection{Devolution Structure of Maternal Health Care}

The study further sought to determine the extent to which devolution structure in the health care had affected the provision of maternal health care. The findings are represented in table 4.

\begin{tabular}{|c|c|c|c|c|}
\hline & & Mean & \% mean & Std. Deviation \\
\hline B1 & $\begin{array}{c}\text { The clinic infrastructure is able to cater for the needs of all } \\
\text { the pregnant mothers in the sub county }\end{array}$ & 2.71 & $54.2 \%$ & 1.25506 \\
\hline B2 & $\begin{array}{c}\text { The clinic has all the facilities it requires for providing } \\
\text { satisfactory maternal health care to pregnant mothers }\end{array}$ & 2.48 & $49.6 \%$ & 1.18777 \\
\hline B3 & $\begin{array}{c}\text { The hospital is audited and supervised to ensure it achieves } \\
\text { its set objectives for the provision of maternal health care. }\end{array}$ & 2.73 & $54.6 \%$ & 1.28387 \\
\hline
\end{tabular}

Table 3: Influence of Devolution Structure on Maternal Health Care

$$
\mathrm{N}=77
$$

Source: Research Data (2015) 
The findings on the influence of devolution strategy on maternal health care indicate that $54.6 \%$ of the respondents were of the opinion that the hospital is audited and supervised to ensure it achieved its set objectives for the provision of maternal health care; $54.2 \%$ said the clinic infrastructure is able to cater for the needs of all the pregnant mothers in the sub county while $49.6 \%$ said the clinic has all the facilities it requires for providing satisfactory maternal health care to pregnant mothers.

The study also sought to determine the adequacy of the infrastructure to provide maternal health care. The findings on whether the equipment was adequate are presented in figure 4.1

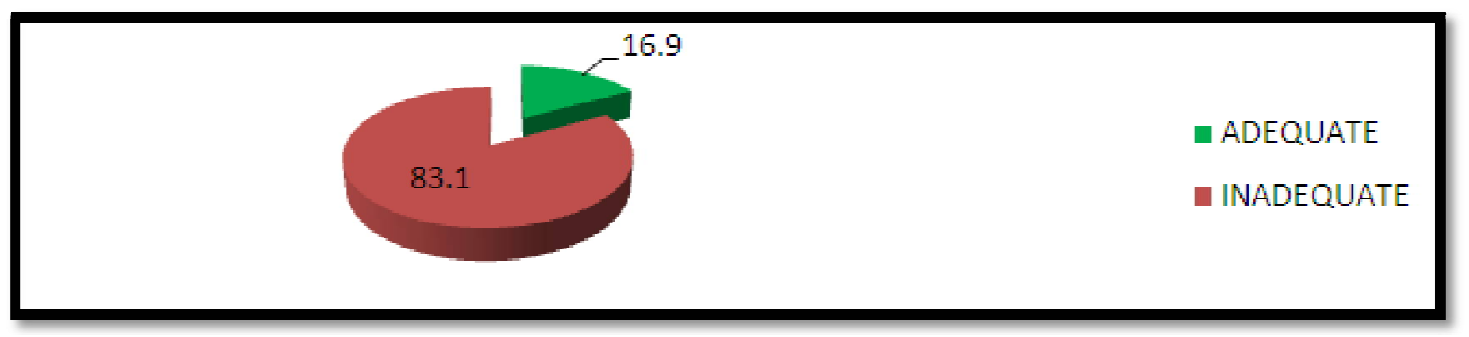

Figure 2: Adequacy of Infrastructure in Maternal Health Care $\mathrm{N}=77$

Source: Research Data (2015)

The findings on the adequacy of infrastructure for maternal health care indicate that $83.1 \%$ of the respondents were of the opinion that the infrastructure was inadequate while $16.9 \%$ indicated that the infrastructure was adequate. The explanations given by the respondents on the adequacy and inadequacy of the infrastructure include; the demand for the services was greater that the supply in terms of bed capacity, facilities, equipment needed and health workers.

A comparison of the adequacy of these facilities before and after devolution of maternal health indicate that no change since the infrastructure remains to be same while where any increase was experienced the demand also went high nullifying the increase.

\subsection{Devolution Systems of Maternal Health Care}

The study sought to determine the extent to which devolution systems in the health care had affected the provision of maternal health care. The findings are represented in Table 4

\begin{tabular}{|c|c|c|c|c|}
\hline & Mean & \% mean & Std. Deviation \\
\hline C1 & $\begin{array}{c}\text { The maternal health care is regulated through the health } \\
\text { information system at the sub county }\end{array}$ & 3.29 & $65.8 \%$ & 1.23392 \\
\hline C2 & $\begin{array}{c}\text { Monitoring and evaluation systems of the indicators of } \\
\text { maternal health care are used to control provision of the } \\
\text { service }\end{array}$ & 3.60 & $72 \%$ & 1.09135 \\
\hline C3 & $\begin{array}{c}\text { Supply chain systems are used to ensure sufficient medication } \\
\text { for pregnant mothers at the hospital }\end{array}$ & 3.06 & $61.6 \%$ & 1.38922 \\
\hline
\end{tabular}

Table 4: Influence of Devolution Systems on Maternal Health Care

$$
\mathrm{N}=77
$$

Source: Research Data (2015)

The findings on the influence of devolution systems on maternal health care indicate that $72 \%$ of the respondents were of the opinion that monitoring and evaluation systems of the indicators of maternal health care are used to control provision of the service, $65.8 \%$ said the maternal health care is regulated through the health information system at the sub county while $61.6 \%$ said Supply chain systems are used to ensure sufficient medication for pregnant mothers at the hospital

The study findings also indicate that the new systems had been introduced in the last one year to assist in provision of maternal health care mobile clinics, introduction of comprehensive reproductive health training while in some station nothing had really changed. The effectiveness of the systems introduced were difficult to evaluate since they were in the introductory phases while there was lack of capacity for the employees hence not very effective.

\subsection{Devolution of Staff in Maternal Health Care}

The study sought to determine the extent to which devolution of staff in the health care had affected the provision of maternal health care. The findings are represented in Table 5 


\begin{tabular}{|c|c|c|c|c|}
\hline & Mean & \% mean & Std. Deviation \\
\hline D1 & $\begin{array}{c}\text { The hospital has sufficient doctors and nurses to take care of the } \\
\text { pregnant mothers }\end{array}$ & 2.22 & $44 \%$ & 1.18791 \\
\hline D2 & All doctors and nurses undergo further training in maternal health care & 2.70 & $54 \%$ & 1.22544 \\
\hline D3 & $\begin{array}{c}\text { The HR departments ensures good work environment for staff to } \\
\text { provide efficient maternal health care }\end{array}$ & 2.48 & $49.6 \%$ & 1.31400 \\
\hline
\end{tabular}

Table 5: Influence of Devolution of Staff on Maternal Health Care

$\mathrm{N}=77$

Source: Research Data (2015)

The findings on the influence of devolution of staff on maternal health care indicate that $54 \%$ were of the opinion that all doctors and nurses undergo further training in maternal health care, $49.6 \%$ said the HR departments ensures good work environment for staff to provide efficient maternal health care while $44 \%$ said the hospital have sufficient doctors and nurses to take care of the pregnant mothers.

The study findings also indicate on the capacity of human resource at the hospitals to manage maternal health care that the inadequate number of staff who cannot be able to provide quality health care and there is also need to increase their skills.

The study also determined that the doctors and nurses had at least taken training within the last year and therefore their training was frequent.

The study findings on the work environment for the doctors and nurses in relation to provision of maternal health care indicated that they did not have a good working environment since they had poor infrastructure, which hunting, lack of motivation, threats, frequent transfers, lack of supplies necessary for delivering services, strain a lot due to acute shortage of staff lack incentives and lack of opportunities for further training.

\section{Discussion of Findings}

The findings on the work experience of the respondents indicate that $54.5 \%$ had a work experience of over 13 years, $23.4 \%$ of between $8-12$ years, $18.2 \%$ between $4-7$ years and 3.9\% of less than 3years. These findings indicate that the respondents had worked for a considerably long period of time and therefore were in a position to give an informed perspective to the study. The period they had been in the institutions gave them an advantage of information and therefore was very suited for the study.

The findings on the period of time the respondents had been in their current position indicate that $40.3 \%$ for a period of between $4-7$ years, 33.8\% less than 3 years, $15.6 \%$ for over 13 years while $12.4 \%$ were for a period between 812 years. These findings indicate that the respondents had worked in their current position for a considerable period of time and therefore were aware of what happened; they therefore could give information from an informed point of view for the study. The respondents had worked for different periods of time and therefore this would ensure that the researcher got the information from different perspectives and therefore more informed

\subsection{Devolution Strategy and Maternal Health Care}

The findings on the effect of devolution strategy of maternal health care indicate that a majority of the respondents were of the opinion that there were defined strategies as to how to reach more pregnant mothers in the rural areas. These findings indicate that there were strategic plans that were made with the aim of reaching pregnant mothers in the rural areas

These findings concur with studies done by Atienza (2004) in Philippines who asserted that since devolution in the Philippines, health workers have become more hands-on in their approach, more visible in the communities, and much closer to the people. They were therefore able to provide services to those in need with ease since they are close to them. Musgrave (1959) further states that decentralization can enhance productive efficiency by reducing bureaucratic filters and minimizing the likelihood of conflicts between elected officials and civil servants. The sub national governments are better positioned to overcome information asymmetry and hence tailor policies and service provision according to local preferences and needs.

The study findings also indicated that some of the new policy documents that were developed relating to maternal health care provision were free maternity services, beyond zero campaign and mobile clinics although not uniformly done in all areas.

Empirical evidence on the impact of devolution depicts mixed results and in some cases it was inconclusive. For example, a study of the federal state of India suggested that decentralization promoted government responsiveness in service delivery, especially if the media was very active at the local level (Besley and Burgess, 2002). A study in Italy indicated that devolution could exacerbate regional disparities in public spending and economic outcomes (Calamai, 2009). Azfar et al (2001) finds that local officials have limited authority to influence service delivery while citizens' influence at the local level is hampered by limited information.

As a result, devolution does not achieve the desired effects of allocate efficiency. The study determined that health care before and after the devolution in terms of policy change and its effectiveness in provision of maternal health care provision had increased in maternal health care demand bringing the services close to the people although strained in capacity. Atienza (2004) concurred saying that despite the lack of medicines, more people now troop to these health 
facilities for services. This is true in this study since as a result of devolution and the provision of free maternal health care the demand for the services has increased.

This concurs with a study conducted by Saunders (2004) whose findings indicated that maternal health policy is a key component to good development especially with the decentralization of maternal health services. There is need to pay attention to reducing child mortality and morbidity results in healthier children who can attend school and eventually contribute to economic growth when they become wage-earners.

These findings also reinforce the statistics of the world health organization which identified Kenya is one of the countries having a "critical shortage" of healthcare workers. The WHO has set a minimum threshold of 23 doctors, nurses and midwives per population of 10000 as necessary for the delivery of essential child and maternal health services. Kenya's most recent ratio stands at 13 per 10000 (World Health Organization, 2010)) This shortage is markedly worse in the rural areas where, as noted in a recent study by Transparency International, under-staffing levels of between 50 and 80 percent were documented at provincial and rural health facilities (Transparency International - Kenya, 2011)

\subsection{Devolution Structure and Maternal Health Care}

The findings on the influence of devolution structure on maternal health care indicate that a majority of the respondents were of the opinion that the hospital is audited and supervised to ensure it achieves its set objectives for the provision of maternal health care. These findings concur with studies conducted in Ghana, Ethiopia and Thailand where it is seen that creating the right governance and accountability structure is critical in making devolution and, in the end, service delivery to the patient, successful

These findings concur with Owo (2012) who said that despite decentralization of the various health services including maternal health care systems, there is need to review policy at the grass root level on how supplies will reach the local clinics. Consequently, the study recommended that laws relating to pharmaceutical at the county and national levels be reviewed to ensure that they do not hamper the devolution process. This therefore shows the need for auditing to ensure the accomplishing devolution objectives.

The findings on the adequacy of infrastructure for maternal health care indicate that a majority of the respondents (83.1\%) were of the opinion that the infrastructure was inadequate. The explanations given by the respondents on the adequacy and inadequacy of the infrastructure include; the demand for the services was greater that the supply in terms of bed capacity, facilities, equipment needed and health workers.

These findings concur with a study carried out in India by Omen (2011) who said that Infrastructure and Equipment forms a critical part of maternal health service delivery in a decentralized kind of a system. Availability, Accessibility, Affordability, Equity, Efficiency and Quality of MHC services highly depend on the distribution, functionality and quality of infrastructure. There is therefore need to ensure the adequacy of supplies required for the service delivery in order to ensure that the devolution process is a success

A comparison of the adequacy of these facilities before and after devolution of maternal health indicate that no change since the infrastructure remains to be same while where any increase was experienced the demand also went high nullifying the increase. This is further supported by Omen (2011) who said most developing countries have invested substantially in developing health infrastructure in rural areas which provides a base for extending MHC services to the poor. Still, there is clear evidence that in many countries there are gaps and inadequacies in health infrastructure. The functionality and utilization of health infrastructure has been sub-optimal or poor due to a variety of reasons. Inadequate priorities for health infrastructure by the health managers and politicians, as well as insufficient funds from the government, are the main causes for the poor state of health infrastructure in many developing countries.

\subsection{Devolution Systems and Maternal Health Care}

The findings on the influence of devolution systems on maternal health care indicate that a majority of the respondents were of the opinion that the monitoring and evaluation systems of the indicators of maternal health care are used to control provision of the service. The finding on the use of monitoring and evaluation as a control tool in the provision of maternal health is in agreement with the study by Obagen (2010) in Nigeria which noted that devolution in Nigeria was mainly not achieving the required goals due to a lack of a monitoring and evaluation mechanism. This had led to wastages and financial mismanagement of resources as framework which would ensure that the budgets were controlled and operational frameworks were used to guide processes. The study recommended the implementation of monitoring and evaluation framework as systems which would ensure that the process of devolution was used to achieve desired goals and objectives. These findings are also supported by Kinchi (2012) in a study conducted Philippines who noted that any devolved system of governance cannot function effectively if a proper monitoring and evaluation framework is not in place irrespective of the strategies and structures in place. This was construed to imply that devolved maternal health care also requires proper monitoring and evaluation.

The study findings also indicate that the new systems had been introduced in the last one year to assist in provision of maternal health care were ICT, mobile clinics and introduction of comprehensive reproductive health training. The finding on the introduction of new systems and gadgets including mobile applications and other ICT resources is supported by the finds by Karumbe (2009) who noted that for any system to achieve the desired user results it must be user friendly while at the same time achieving the desired results. For this to be possible, it is essential that applications such as mobile application which ease access of systems offering should be incorporated. This ensures that the system is usable by users and readily available. In relation to the facilities introduced as a result of the devolved maternal health care in Kenya to support the maternal health systems, this is viewed as a step in the in the right direction. This new device would assist in making the devolved maternal health systems more effective and efficient. 
The effectiveness of the systems introduced were difficult to evaluate since they were in the introductory phases while there was lack of capacity for the employees hence more time in needed to evaluate. Findings suggesting that it is difficult to measure current devolution achievements are also supported by the findings by Caren (2013) who noted that any new system is bound to face a number of challenges especially in the initial stages where its monitoring information may not give satisfactory evidence as to its exact nature of operations. This means that in the early implementation phases, the system still requires critical assessment to ensure its success. The system according to Gushi (2012) is however meant to improve as operations such as optimization and training of users improves.

\subsection{Devolution of staff and Maternal Health Care}

The findings on the influence of devolution of staff on maternal health care indicate that a majority of the respondents were of the opinion that all doctors and nurses had undergone some training in maternal health care. This could be attributed to the fact that Uasin Gishu training program is majorly partner supported. Trainings on emergency maternal and obstetric care, family planning and comprehensive reproductive health have been ongoing due to their support.

These findings however were in disagreement with Karere (2014) findings who noted that doctors and nurses have not received further training on maternal health since the introduction of the devolved system of governance in Kenya. This is despite the ministry of health directives and recommendations that doctors and nurses undergo training on the devolved maternal health. This could be as a result of the shortages of cash at the county level where the training is supposed to be financed. The county governments have not taken the concept of training the health workers seriously on the devolved maternal health care. They have however concentrated on other development agendas including the construction of roads among other priorities leaving out the medics training. The report therefore recommended a review of such policies where health workers are not given training priorities on the devolved maternal health care. There was therefore training in Uasin Gishu County because they were supported by many donor organizations such as the world health organization and so forth

The study findings on the capacity of human resource at the hospitals to manage maternal health care indicate that the number of staff was inadequate and could not be able to provide quality health care due to excessive workload. These therefore indicate that as a result of devolution the staff became inadequate since they were needed in many stations that had been newly opened and staff rationalization program which was still going on. These findings differ from studies done by Atienza (2004) who said that while there are still problems, the presence of a relatively higher number of health personnel and improved health facilities and services compared to pre-devolution years contributed to overall health performance. In this case the number of personnel increased while the personnel in the Kenyan system decreased since the country is forced to redistribute the few personnel they already have to new established stations.

The study also determined that the doctors and nurses had at least taken training within the last year and therefore their training was frequent. The study findings on the work environment for the doctors and nurses in relation to provision of maternal health care indicated that they did not have a good working environment since they had poor infrastructure, witch hunting, lack of motivation, threats, frequent transfers, political interference, lack of supplies necessary for delivering services, strain a lot due to acute shortage of staff lack incentives and lack of opportunities for further training.

These findings on the poor work environment expand the findings of a study conducted by Victoriano (2013) in Kenya who had said that the Ministry of health requires mechanisms to mediate disputes regarding the transfer of human resources that may arise between the central and local levels. Chief officials at the decentralized management level may, for legitimate reasons of efficiency or resource constraint, refuse to accept particular posts into their organizational structure. Differences in personality or political views between local health staff and local politicians may make the appointment of a particular individual to that geographic area very difficult. Even if the central level retains the legal power to force the appointment, the success of the health worker in performing his or her duties in such situation is apparently threatened.

The findings also concur with Atienza (2004) who said Health personnel in devolved systems lost many benefits protected by national laws. Local politics and vested interests of local leaders now threaten their positions and responsibilities. Also, many LGUs now face common problems, including those that were able to improve health service delivery. These include resource constraints in construction and improvement of health facilities, health workers' benefits, and overall health improvements; inefficiency and politicization in the management of some resources for public health, like medicine procurement; and the general lack of local government health personnel and facilities. It seems that the absence of exhaustive deliberations and the hasty implementation of health devolution partly explain some of these problems, confirming the World Bank's comments that based on available anecdotal evidence worldwide, poorly designed and hastily implemented decentralization has serious consequences for health service delivery (World Bank Group n.d.).

\subsection{Secondary Data on Provision of Maternal Health Care}

The study sought to analyze secondary data that was collected from the various sub counties relating to the provision of maternal health care. The data collected covered the uptake of family planning, the $4^{\text {th }}$ ANC visits and the number of skilled deliveries that were conducted in the stations. These findings are presented as follows;

\subsection{Family Planning Uptake}

The study first sought to determine the trend of uptake of family planning. This was done by analyzing the uptake before the devolution and uptake after the devolution. The findings indicated variations in the different centers. Where 
some sub-county the uptake marginally decreased with devolution such as Ainabkoi, Kesses and Soy; the uptake however increased to a greater extent in Kapseret, Moiben and Turbo as represented by figure;

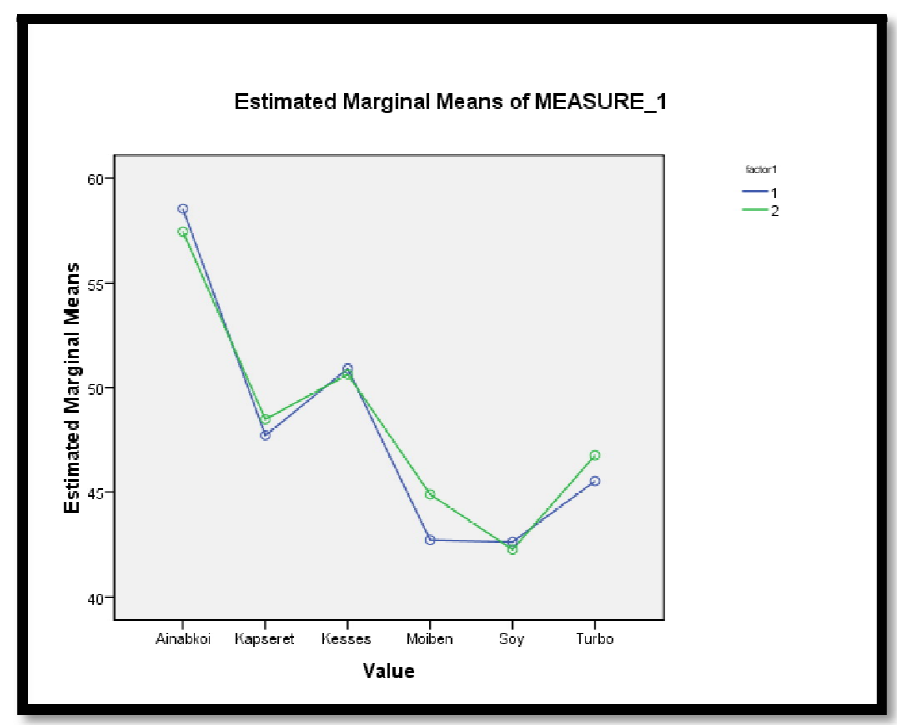

Figure 3: Family Planning Uptake

$$
\mathrm{N}=77
$$

Key: 1- Before Devolution, 2- After Devolution

Source: Research Data (2015)

Based on these findings the study sought to determine the significances of the increases and the decreases in the various sub-county hospitals and the results were presented in Table 6

\begin{tabular}{|c|c|c|c|c|c|}
\hline \multicolumn{7}{|c|}{ Tests of Between-Subjects Effects } \\
\hline Source & Type III Sum of Squares & Df & Mean Square & F & Sig. \\
\hline Intercept & 153456.775 & 1 & 153456.775 & $1.656 \mathrm{E} 3$ & .000 \\
\hline value & 316.477 & 1 & 316.477 & 3.416 & .069 \\
\hline Error & 5930.162 & 64 & 92.659 & & \\
\hline \multicolumn{7}{|l|}{ Table 6: Significance of the Variations in Family Planning Uptake (ANOVA) } \\
N=77
\end{tabular}

Source: Research Data (2015)

The results indicated a significant variation $(p=0.000)$ in the rate of increase compared to the rate of decrease. This meant that the rate of decrease was much smaller compared to the rate of increase after devolution. This meant that despite decreases in certain sub-counties, there was a much more significant increase in other sub county hospitals. To illustrate the effect, Figure 3was used.

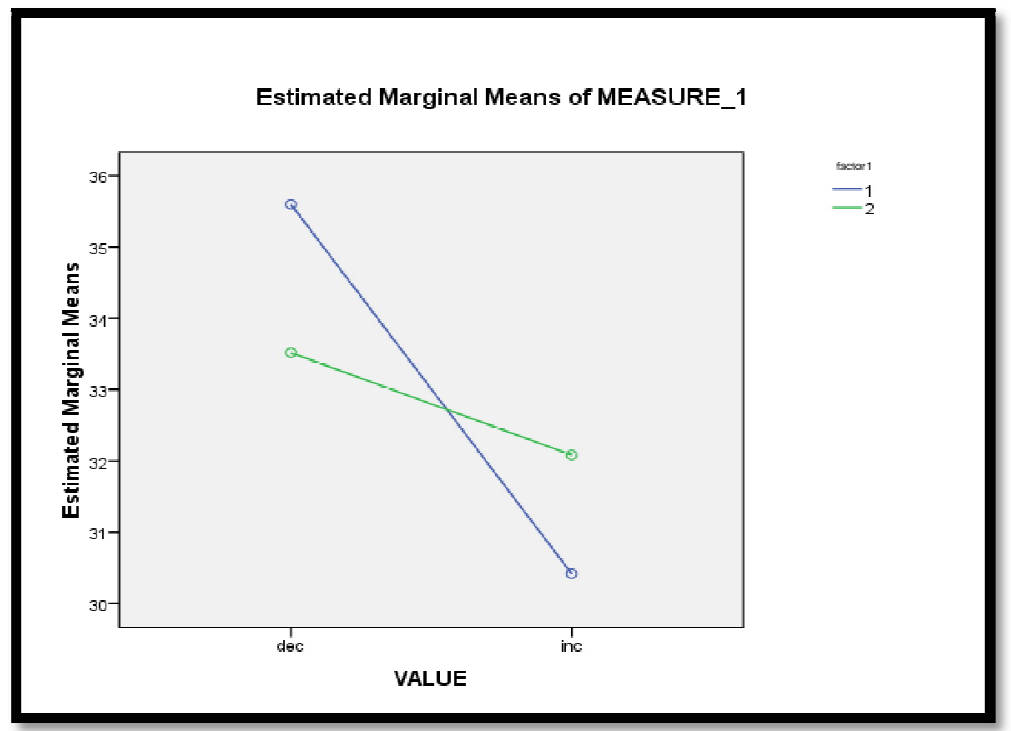

Figure 4: Significance of the Variations in Family Planning Uptake $\mathrm{N}=77$

Source: Research Data (2015) 
The results variations after devolution were interpreted to mean that there was a much more equitable distribution of resources hence the trends in over crowed centers that were offering family planning relocated to centers near their home areas where the resources may not have been available initially. The fact that the rate of increase was more than the rate of decrease could be interpreted to mean that the uptake generally in the family planning after devolution rose which was a perceived benefit of the prices of devolution

\subsection{Mothers Number of Post Natal Visits}

The study sought to establish the number of mothers who made it to the $4^{\text {th }}$ visit of pre-natal care before and after devolution in the identified sub-counties. The study results were presented in Figure 5.

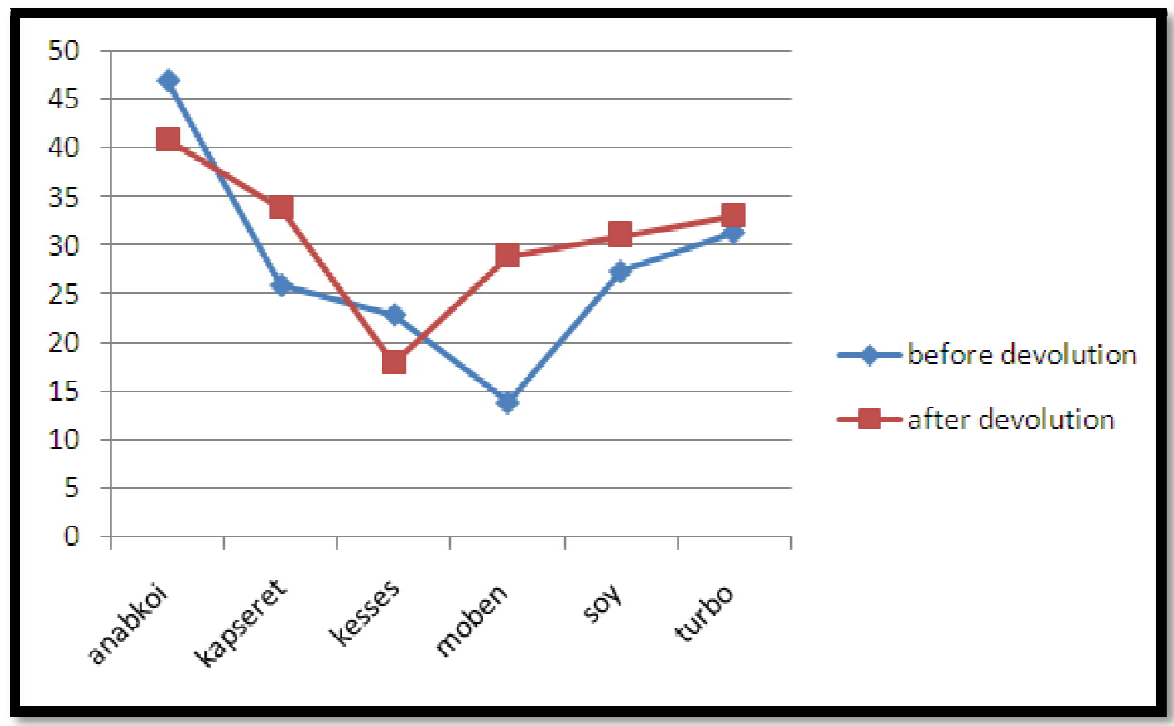

Figure 5: Mothers Number of Post Natal Visits (4th Visit Data)

$\mathrm{N}=77$

Source: Research Data (2015)

The study findings indicated there were variations in the number of mothers reaching the $4^{\text {th }}$ pre-natal visit before and after devolution. The sub counties where the number of visits went down included Ainabkoi, and Kesses while the number of pre-natal visits to the $4^{\text {th }}$ visit when up in Kapseret, Moiben, Soy and Turbo.

\begin{tabular}{|c|c|c|c|c|c|}
\hline \multicolumn{7}{|c|}{ Tests of Between-Subjects Effects } \\
\hline Source & Type III Sum of Squares & Df & Mean Square & F & Sig. \\
\hline Intercept & 60700.641 & 1 & 60700.641 & 301.194 & .000 \\
\hline value & 1.668 & 1 & 1.668 & .008 & .928 \\
\hline Error & 14107.328 & 70 & 201.533 & & \\
\hline
\end{tabular}

Table 7: Significance of the Variations in 4th Visit of Prenatal Care (ANOVA)

$$
\mathrm{N}=77
$$

Source: Research Data (2015)

The results indicated a significant variation $(p=0.000)$ in the rate of increase compared to the rate of decrease. This meant that the rate of decrease was much smaller compared to the rate of increase after devolution. This meant that despite decreases in certain sub-counties, there was a much more significant increase in other sub county hospitals. To illustrate the effect, Figure 6was used. 


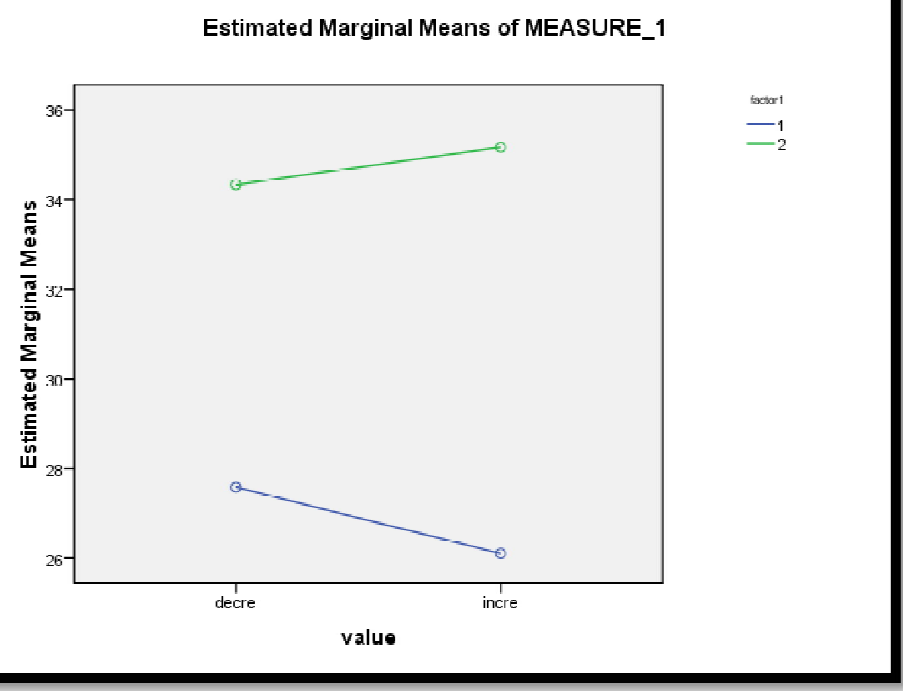

Figure 6: Significance of the Variations in 4th

Visit of Prenatal Care (ANOVA)

$\mathrm{N}=77$

Source: Research Data (2015)

The results variations after devolution on the number of mothers who made it to the $4^{\text {th }}$ were interpreted to mean that there was a much more equitable distribution of resources hence the trends in over crowed centers that were offering pre-natal care relocated to centers near their home areas where the resources may not have been available initially. The fact that the rate of increase was more than the rate of decrease could have been interpreted to mean that the level of facilities including number of doctors conducting the pre-natal care in some of the centers after devolution could have improved which was a perceived benefit of the prices of devolution

\subsection{Number of Skilled Deliveries}

The study sought to establish the number of skilled deliveries before and after devolution. This implied the number of mothers who attended the identified hospital during birth to give birth with the help of a skilled medical professional.

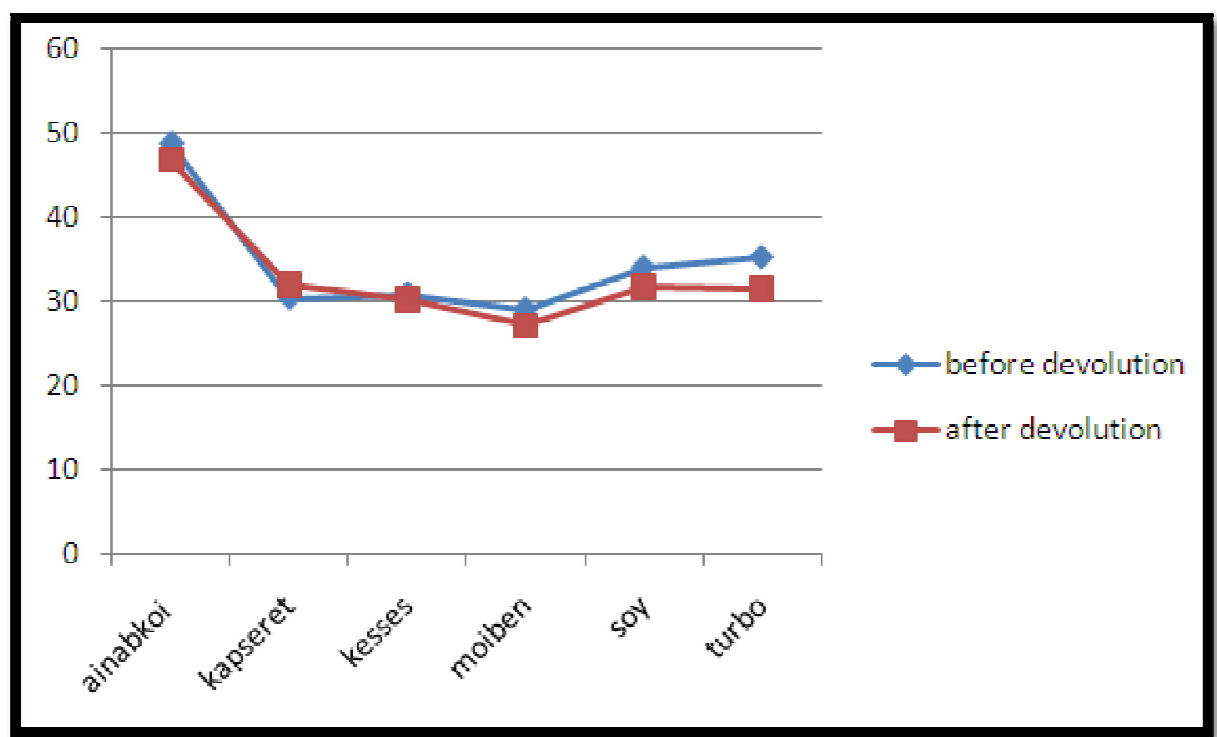

Figure 7: Number of Skilled Deliveries

$$
\mathrm{N}=77
$$

Source: Research Data (2015)

The findings indicated that the there were no major variations in the number of mothers who sought the help of medical professionals in the hospitals before and after devolution. The study findings not only slight differences in the average numbers per sub county with Ainabkoi, Moiben Soy and Turbo recording slight decreases while Kapseret recorded a slight increase but there was no major change in Kesses. 


\begin{tabular}{|c|c|c|c|c|c|}
\hline \multicolumn{7}{|c|}{ Tests of Between-Subjects Effects } \\
\hline Source & Type III Sum of Squares & Df & Mean Square & F & Sig. \\
\hline Intercept & 43307.367 & 1 & 43307.367 & 542.573 & .055 \\
\hline Value & 109.451 & 1 & 109.451 & 1.371 & .246 \\
\hline Error & 5587.296 & 70 & 79.819 & & \\
\hline
\end{tabular}

Table 8: Significance of the Number of Skilled Deliveries (ANOVA)

$\mathrm{N}=77$

Source: Research Data (2015)

The study findings indicated no significant changes $(p=0.055)$ in the number of skilled deliveries in the county. This was interpreted to mean that changes in devolution may not have affected the number of skilled deliveries in the county. This could have been as a result of the fact that devolution was still gaining roots in the county and its effects would be felt with time as potential expectant mothers continued to learn about where to visit in case, they wanted to received a skilled delivery.

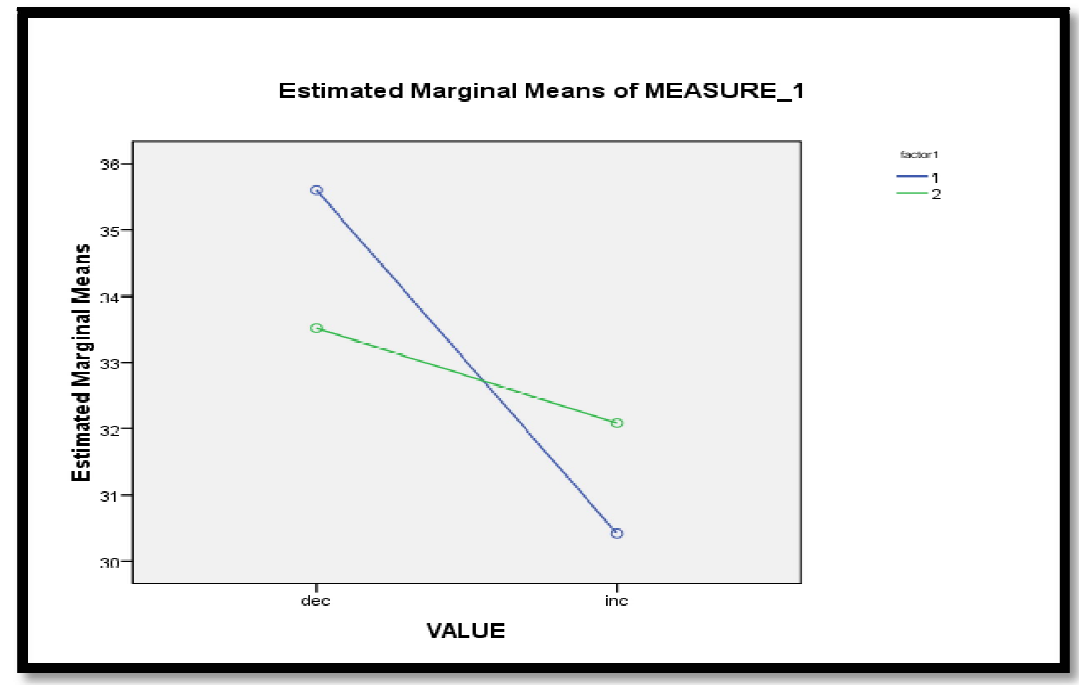

Figure 8: Significance of the Number of Skilled Deliveries (ANOVA) $\mathrm{N}=77$

Source: Research Data (2015)

The rate of change in the increase and the decrease was consequently fairly even indicating that changes in the number of skilled deliveries after devolution would be felt in the long run as devolution continued to gain roots in the county. This was interpreted as an indicator for the need of more effort to ensure that devolution was understood by the local residents and its impacts could be reaped by the residents.

\subsection{Correlations} Table 10

The study sought to determine the correlation between the independent variable. The findings are represented in

\begin{tabular}{|c|c|c|c|c|c|}
\hline & & Strategy & Structure & Systems & Staff \\
\hline \multirow{3}{*}{ Strategy } & Pearson Correlation & 1 & $.399^{* *}$ & $.346^{* *}$ & $.412^{* *}$ \\
\cline { 2 - 6 } & Sig. (2-tailed) & & .000 & .002 & .000 \\
\cline { 2 - 6 } & $\mathrm{N}$ & 77 & 77 & 77 & 77 \\
\hline \multirow{3}{*}{ Structure } & Pearson Correlation & $.399^{* *}$ & 1 & $.593^{* *}$ & $.552^{* *}$ \\
\cline { 2 - 6 } & Sig. (2-tailed) & .000 & & .000 & .000 \\
\cline { 2 - 6 } & $\mathrm{N}$ & 77 & 77 & 77 & 77 \\
& Pearson Correlation & $.346^{* *}$ & $.593^{* *}$ & 1 & $.387^{* *}$ \\
\hline \multirow{3}{*}{ Staff } & Sig. (2-tailed) & .002 & .000 & & .001 \\
\cline { 2 - 6 } & $\mathrm{N}$ & $.472^{* *}$ & $.552^{* *}$ & $.387^{* *}$ & 1 \\
\cline { 2 - 6 } & Pearson Correlation & .000 & .000 & .001 & 77 \\
\cline { 2 - 6 } & Sig. (2-tailed) & 77 & 77 & 77 & 77 \\
\cline { 2 - 6 } & $\mathrm{N}$ & 77 & & 77 & \\
\hline
\end{tabular}

Table 9: Correlations of the Independent Variables

$$
\mathrm{N}=77
$$

**. Correlation Is Significant at the 0.01 Level (2-Tailed)

Source: Research Data (2015) 
The findings indicate that there was a significant correlation between strategy and structure $(p=0.000)$, strategy and systems $(p=0.002)$, strategy and staff $(p=0.000)$, systems and structure $(p=0.000)$ staff and structure $(p=0.000)$ and staff and systems $(\mathrm{p}=0.001)$.

These findings indicate that all the independents variables were significantly correlated and had a significant relationship. These therefore imply that all the variables affected each other significantly. This could be attributed to the fact that the strategy, systems, structures and staff all work hand in hand in the provision of maternal health care and the slack or breakdown of one section affects all the others significantly.

\section{Regression Analysis}

The researcher sought to compute the regression model for the study in an effort to understand the effect of devolution on the maternal health care. The study findings were as presented in Table 10

\begin{tabular}{|c|c|c|c|c|c|c|}
\hline \multicolumn{7}{|c|}{ Model Summary } \\
\hline & Model & $\mathrm{R}$ & R Square & Adjusted R Square & $\mathrm{F}$ & Sig. \\
\hline & 1 & $.957 \mathrm{a}$ & 0.827 & 0.678 & 2.591 & $.004^{\mathrm{a}}$ \\
\hline \multicolumn{7}{|c|}{ Coefficients $^{a}$} \\
\hline \multirow{2}{*}{\multicolumn{2}{|c|}{ Model }} & \multicolumn{2}{|c|}{$\begin{array}{l}\text { Unstandardized } \\
\text { Coefficients }\end{array}$} & $\begin{array}{c}\text { Standardized } \\
\text { Coefficients }\end{array}$ & \multirow[t]{2}{*}{$\mathrm{T}$} & \multirow[t]{2}{*}{ Sig. } \\
\hline & & B & Std. Error & Beta & & \\
\hline \multirow[t]{5}{*}{1} & (Constant) & 3.926 & 0.363 & & 10.812 & 0 \\
\hline & Strategy & -0.021 & 0.102 & 0.025 & 0.202 & 0.840 \\
\hline & Structure & 0.388 & 0.132 & 0.455 & 2.952 & 0.004 \\
\hline & Systems & -0.056 & 0.115 & 0.067 & 0.483 & 0.630 \\
\hline & Staff & -0.237 & 0.113 & 0.288 & 2.098 & 0.039 \\
\hline
\end{tabular}

Table 10: Regression Model on Maternal Health Care $\mathrm{N}=77$

a. Dependent Variable: Provision of Maternal Health

Source: Research Data (2015)

The study findings indicated that $82.7 \%$ of the maternal healthcare data could be accounted for in the model ( $\mathrm{R}$ Square $=0.827$ ) while the computation of the model was significant to imply that the model had been correctly computed $(\mathrm{p}=0.004)$

The coefficients in the regression equation were used to compute the regression equation as follows;

$\mathrm{Y}=3.926+0.025$ (Strategy) + 0.455 (Structure) + 0.067 (Systems) + (0.288) Staff + 0.363 (Error Rate)

These results were interpreted to mean that structure were the most important determinants of maternal health care contributing about $45.5 \%$ in the provision of maternal health care. Staff was also an important consideration in improving maternal health care contributing about $28.8 \%$ in the provision of maternal health care. Strategy (2.5\%) and system $(6.7 \%)$ were essential but their contribution was much minimal in comparison to structure and staff.

\section{Conclusions and Recommendations}

The study concluded that devolution strategy on maternal health care was important only to the extent of assisting in the governing of maternal health services but it did not directly influence provision of maternal health care. This meant that the strategy was mainly useful for management operations but their direct benefits were not felt by the service providers in the county. The study however noted that structures introduced by the county were a major contributor to the provision of maternal health care. Systems that enabled the provision of maternal health care however did not have any significant unlike staffs that were noted to significantly affect the provision of maternal health services. The training of the medical professionals after devolution and the efforts by the Human Resource departments ensures good work environment leading to improve maternal health care.

\section{Recommendations}

- The county health care management should target to improve demand of maternal services by widening awareness maternal health services and strive to improve the negative perceptions on quality of maternal service delivery in the county

- Targeted Staff training is a motivator to better maternal health care. The county should therefore build the capacity of staff that would aid in the provision of the maternal health care. 


\section{References}

i. $\quad$ Agyepong P. (1999). Decentralization and the Social Economics of Development: Lessons from Kenya. Nairobi: CAB International

ii. Aitken, D. (2009). Devolution of Health Systems in Ghana, Zambia, Uganda and the Philippines: A Comparative Analysis of Decision Space. Harvard School of Public Health, Boston, MA, USA and New York University of Law, New York, NY, USA.

iii. Azfar, O., Kahkonen, S. and Meagher, P., (2001) Conditions for effective decentralization governance: A synthesis of research findings; IRIS Center, University of Maryland Working Paper No 256 Available at: http:// www.iris.umd.edu/ download.aspx?ID b587c7e7 919f 46f1 b166 1297ba15818a. [Accessed 19th Nov 2009]

iv. Banting J. Corbett M. (2002). Democracy and Devolution in South Asia and West Africa: Participation, Accountability and Performance, Cambridge: Cambridge University Press

v. Barrow, (2014). Devolution and Poverty-Alleviation Developing Countries: A Comparative Analysis or, is West Bengal Unique? IDSWorking Paper 130, Brighton: IDS

vi. Bennis K. (2012) "On the measurement and impact of fiscal devolution", Tax Policy Center, Washington DC.

vii. Besley, T. and Burgess, R., (2002) The political economy of government responsiveness: Theory and evidence. Quarterly Journal of Economics, Vol 117 (4), 1415 - 1451.

viii. Bilsend, M. (2014). Democracy and Devolution in Kenya: Participation, Accountability and Performance (Duresh Press), Nairobi

ix. $\quad$ Bossert, A. M., Desta, A., Tekle, K. and Mweta, E. (2007). Pursuing Better Health Care Delivery at District Level. World Health Forum, 13:31-37.

x. Calamai, L. (2009). The link between devolution and regional disparities: Evidence from the Italian regions. Environment and Planning Journal, Vol 41, pp 1129 - 1151

xi. $\quad$ Doents, R. (2013). 'Devolution in Zimbabwe: A Local Perspective', Public Administration and Development 23.1: $115-25$

xii. $\quad$ Doesentin, (2012). Urban Public Finance in Developing Countries, Oxford University Press, New York.

xiii. Hardee \& Smith, (2000). "Decentralization and Government Provision of Public Goods: The Public Health Sector in Uganda." Abt Associates: MEASURE Evaluation Project Working Paper No. 01-35, Bethesda, MD.

xiv. Kalisten, K. (2012). A realistic approach to the evaluation of the quality management movement in health care systems: a comparison between European and African contexts based on Mintzberg's organizational models. International Journal of Health Planning and Management 19: 337-364. Central Bureau of Statistics, Kenya Medical

xv. Kaliston, W. (2013) Secretary for Health, Government of Mexico. Presentation at Harvard University, JF Kennedy School of Government.

xvi. Karim, R. (2013). Water markets, market reform and the urban poor: Results from Jakarta, Indonesia, World Developmen reviewt, Vol. 22.

xvii. Kayneshs, (2014). 'Does Devolution Contribute to Poverty Reduction? Surveying the Evidence', in P.P. Houtzager and M. Moore (eds), Changing Paths: International

Arbor: University of Michigan Press: 233-59

xviii. Kenya Demographic Health Survey (2008-2009). Decentralization, Local Governments and Markets: Towards Welfare Agenda, Clarendon Press, Oxford.

xix. Kledze S. (2013) the state of maternal health care infrastructure in the rural areas. Journal of Health Policy 32:215-243.

xx. Langer et al. (2000). Decentralizing Swedish Health Care Euro health, 6,3 pp.34- 35: Summer.

xxi. March and Simon (2012). "Fiscal Devolution: is it happening? How do we know?", paper prepared for the Conference on Public Finance in Developing Countries, Georgia State University.

xxii. Maria Ela Atienza (2004) The Politics of Health Devolution in the Philippines: Experiences of Municipalities in a Devolved Set-up

xxiii. Musgrave, R. A. (1959). The theory of public finance: A study in public economy. New York: McGraw Hill

xxiv. Oates W. (1999). 'The Plasticity of Participation: Evidence from a Participatory Governance Experiment', mimeo, Department of Economics, Columbia University

xxv. Oden, A. (2010). The Health Information Systems in maternal health care. Johannesburg: Health Policy Coordinating Unit, March.

xxvi. Omen, G. (2011). The structure of devolved units in maternal health. Journal of Public Administration and Development, 14 (5): 451-458.

xxvii. Otis M. (2013) The importance of systems in maternal health care: Failure and Success, Oxford University Press, London.

xxviii. Owo (2012). The regulation of pharmaceuticals, Center Discussion Paper No. 825, Economic Growth Centre, Yale University.

xxix. Saunders (2004) the strategic position of decentralized maternal health care: The Contradictions of Uganda's Decentralization Program', World Development journal 31.2: $\quad$ 325-37

xxx. Soresh, T. (2013). Action-based Learning to Improve District Management: A Case Study from Tanzania. International Journal of Health Planning and Management, 7, pp. 299-308. 
xxxi. The World Bank. World Bank Fiscal Decentralization Knowledge Programme Team (2012).Devolution Without Disruption: Pathways to a Successful New Kenya

xxxii. Victoriano C. (2013), staffing requirements in the health care industry: Theories, Challenges and Options for Policy', Development Policy Review 19.4: 521-32

xxxiii. Yee D. (2001), Management of staff in a decentralized system of health care, New Delhi: Left Word 